\title{
M. Heinemann: How NOT To Write a Medical Paper
}

Thieme Publishers, Delhi-Stuttgart-New York-Rio de Janeiro, 2016, 95 pp, Euro 9.99

\author{
Dierk Vorwerk
}

(C) Springer Science+Business Media New York and the Cardiovascular and Interventional Radiological Society of Europe (CIRSE) 2016

Dr. Heinemann has authored a small but very entertaining booklet about the musts and must-nots of medical writing. Being an editor himself, Dr. Heinemann gives some very practical tips on how to improve the quality of a medical publication and how to increase the chances for acceptance. The author also adds some good and bad examples related to the subtopic that is discussed, and he describes various traps and potential chances for publication. The booklet benefits from the long-time experiences-and obvious frustrations - of an experienced editor; it is written in a clear and straightforward manner, and is didactically well composed.

The booklet is helpful for those who are just beginning to write medical papers - and for those who may need a reminder or a refresher-about how NOT to write a medical paper. 